\title{
Sistem Pakar Identifikasi Kepribadian Siswa Menggunakan Metode Case-Based Reasoning Berbasis Website
}

\author{
Alvina Islaha ${ }^{1}$, Wildan Wiguna² \\ ${ }^{1,2}$ Program Studi Sistem Informasi, Universitas Adhirajasa Reswara Sanjaya \\ e-mail: ${ }^{1}$ alvinaislaha02@gmail.com, ${ }^{2}$ wildan@ars.ac.id

\begin{tabular}{ccc}
\hline Diterima & Direvisi & Disetujui \\
$12-11-2021$ & $15-11-2021$ & $16-11-2021$ \\
\hline
\end{tabular}

\begin{abstract}
Abstrak - Pencapaian keberhasilan peserta didik dengan budi pekerti yang luhur memerlukan peran pendidik dan orang tua yang memahami aspek penting dalam mendidik siswa. Suatu identifikasi kepribadian memudahkan pengambilan langkah selanjutnya dalam mendidik anak agar dapat menerapkan nilai-nilai kehidupan dengan baik. Mekanisme penanganan kepribadian siswa di SMP IT Daarul Hikmah saat ini masih menggunakan metode observasi secara langung yang kurang terkoordinasi dengan baik antara orang tua siswa dengan pihak sekolah. Pada penelitian ini bertujuan untuk menerapkan metode Case-Based Reasoning (CBR) berbasis website dalam mengidentifikasi kepribadian siswa di SMP IT Daarul Hikmah. Tahapan pengembangan sistem pakar dengan metode CBR tersebut menggunakan model Expert System Development Life-Cycle (ESDLC). Kemudian dilakukan pembangunan website dengan bahasa pemrograman PHP dan basis data MySQL. Hasil penelitian menunjukkan bahwa implementasi sistem pakar menggunakan metode CBR melakukan perhitungan identifikasi kepribadian siswa berdasarkan nilai kemiripan dari kasus baru yang dikaji sesuai dengan bidang keilmuan psikologis. Sistem pakar tersebut memudahkan para orang tua siswa dalam melakukan konsultasi atau diagnosa awal kepribadian anaknya yang mengenyam pendidikan di SMP IT Daarul Hikmah dengan pendataan kasus yang lebih terkoordinasi. Pada hasil evaluasi pengguna terhadap sistem pakar yang telah dikembangkan menunjukkan bukti bahwa responden memberikan umpan balik dengan rata-rata tingkat kepuasan pada kategori baik.
\end{abstract}

Kata Kunci: Metode Pengembangan Sistem Pakar, Identifikasi Kepribadian Siswa, Metode Case-Based Reasoning (CBR), Sistem Pakar Berbasis Website

Abstract - Achieving the success of students with noble character requires the role of educators and parents who understand important aspects in educating students. A personality identification makes it easier to take the next step in educating children so that they can apply life values well. The mechanism for handling student personality at SMP IT Daarul Hikmah currently still uses the direct observation method which is not well coordinated between parents and the school. This study aims to apply the website-based Case-Based Reasoning (CBR) method in identifying the personality of students at SMP IT Daarul Hikmah. The stages of developing an expert system using the CBR method use the Expert System Development Life-Cycle (ESDLC) model. Then the website was built using the PHP programming language and MySQL database. The results showed that the implementation of the expert system using the CBR method calculated student personality identification based on the similarity value of the new cases studied in accordance with the field of psychological science. The expert system makes it easier for parents to conduct consultations or initial diagnoses of the personality of their children who are educated at SMP IT Daarul Hikmah with more coordinated case data collection. The results of user evaluation of the expert system that have been developed show evidence that respondents provide feedback with an average level of satisfaction in the good category.

Keywords: Expert System Development Life-Cycle, Student Personality Identification, Case-Based Reasoning (CBR) Method, Expert System Based on Website

\section{PENDAHULUAN}

Masa remaja berada pada batas peralihan kehidupan anak dan dewasa. Secara fisik mereka tampak sudah dewasa, namun bila diperlakukan layaknya orang dewasa mereka gagal menunjukan kedewasaannya. Pengalaman mereka tentang dunia orang dewasa tentu masih sedikit, sehingga sering terlihat adanya kegelisahan, pertentangan, kebingungan, dan konflik pada diri sendiri. Seharusnya remaja dapat memandang bahwa setiap peristiwa yang dialami akan menentukan perilakunya dalam menghadapi peristiwa-peristiwa tersebut (Ajhuri, 2019). 
Teori konvergensi yang dirintis William Stren menyatakan bahwa seseorang dilahirkan disertai dengan dua pembawaan yaitu baik dan buruk. Bakat pembawaan seseorang akan berkembang dengan baik dengan adanya dukungan lingkungan yang sesuai perkembangan bakatnya. Anak yang memiliki otak cerdas tanpa didukung oleh pendidik yang mengarahkannya maka kecerdasannya tidak akan berkembang. Peserta didik memerlukan bantuan seorang pendidik pada proses belajar untuk mencapai keberhasilan dalam pembelajaran (Sahlan, 2018).

SMP IT Daarul Hikmah merupakan institusi pendidikan berbasis asrama dengan konsep Islamic Boarding School yang menanamkan pendidikan karakter bagi usia remaja. SMP IT Daarul Hikmah didirikan dengan harapan agar generasi penerus memiliki akhlak yang mulia dan dapat menerapkan disiplin yang tinggi. Institusi tersebut memiliki empat kurikulum yaitu kurikulum nasional, tahfidz, pendidikan karakter, dan boarding.

SMP IT Daarul Hikmah dalam mencapai keberhasilan siswa agar memiliki budi pekerti yang luhur, maka pendidik dan orang tua perlu memahami salah satu aspek penting dalam mendidik siswa yaitu mengidentifikasi kepribadian mereka terlebih dahulu. Hal ini akan memudahkan pengambilan langkah selanjutnya dalam mendidik anak supaya dapat menerapkan nilai-nilai kehidupan dengan baik. Namun terbatasnya ruang dan waktu bagi orang tua menyebabkan mereka kesulitan dalam melakukan konsultasi langsung kepada seorang pakar atau ahli psikologi. Adapun metode penanganan kepribadian siswa di SMP IT Daarul Hikmah saat ini dirasa masih kurang tepat dalam melakukan koordinasi pendataan kasusnya. Mekanisme observasi secara langsung yang sedang berjalan memerlukan prosedur dan waktu yang tidak bisa diestimasi dengan optimal. Selain itu, pada SMP IT Daarul Hikmah belum adanya suatu sistem pakar yang dapat digunakan dalam mengidentifikasi kepribadian siswa.

Psikologis pada diagnosa atau penilaian kepribadian dapat menggunakan suatu sistem pakar menggunakan metode Case-Based Reasoning (CBR). Metode ini menggunakan alur dalam penyelesaian kasus dengan menyimpan knowledge baru dari gejala yang ada pada masa lampau (Hardianto, 2018). Pada penelitian rancang bangun sistem pakar penentuan kepribadian dengan metode CBR membantu pasien dan psikolog dalam menganalisa dan menentukan kepribadian (Hardianto \& Kusuma, 2019). Sistem pakar online diagnosis gangguan psikologis menggunakan metode CBR memungkinkan pengguna mengecek kondisi psikologis secara langsung. Hasil diagnosa dapat digunakan sebagai dasar dalam pemeriksaan lebih lanjut (Rahim et al., 2019). Terdapat sistem pakar identifikasi perilaku dan kepribadian siswa dengan metode CBR. Hasilmya membantu guru BK menganalisis, mengidentifikasi, dan memberikan solusi dari perilaku dan kepribadian siswa (Malana \& Hasibuan, 2020).
SMP IT Daarul Hikmah memiliki konsep sekolah asrama berkarakter Rasulullah. Para pendidiknya perlu mengidenifikasi kepribadian siswa secara keseluruhan. Aplikasi sistem pakar diperlukan untuk membantu memahami dan mengidentifikasi setiap kepribadian siswa yang berbeda-beda, agar memudahkan pendidik memberikan penanganan dan pembelajaran sesuai dengan kepribadian siswa. Suatu sistem pakar dapat diimplementasikan menggunakan pemrograman berbasis website (Ernawati et al., 2021). Pada penelitian ini bertujuan untuk menerapkan metode Case-Based Reasoning pada sistem pakar identifikasi kepribadian siswa berbasis website di SMP IT Daarul Hikmah.

\section{METODE PENELITIAN}

\section{Metode Case Based-Reasoning (CBR)}

Metode Case-Based Reasoning (CBR) merupakan proses penyelesaian masalah dengan memanfaatkan pengalaman sebelumnya. Case-Based Reasoning merupakan salah satu metode pemecahan masalah yang dalam mencari solusi dari suatu kasus baru, sistem akan melakukan pencarian terhadap solusi dari kasus lama yang memiliki permasalahan yang sama. Metode ini dapat melakukan penalaran walaupun terdapat data yang tidak lengkap. Ketika proses retrieval dilakukan, ada kemungkinan antara kasus baru dengan kasus lama tidak mirip. Dari ukuran similarity tersebut tetap dapat dilakukan penalaran dan evaluasi terhadap ketidaktepatan data yang diberikan (Gulo \& Syahrizal, 2018).

a. Tahapan pada Case-based Reasoning

Terdapat empat tahapan pada metode CBR yang ditunjukkan pada Gambar 1.

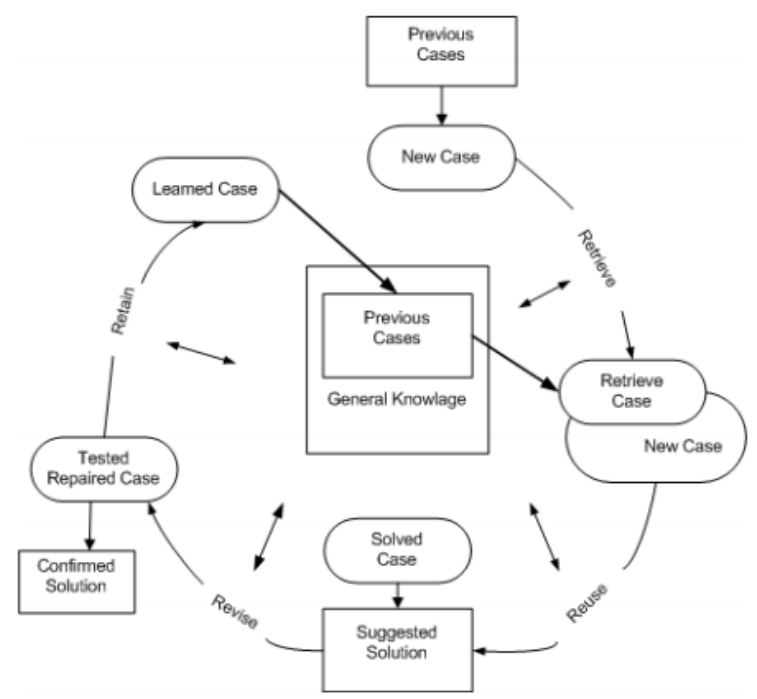

Sumber: (Soroto et al., 2018)

Gambar 1. Siklus Case-Based Reasoning

Pada Gambar 1 menunjunkkan metode Case-based Reasoning sebagai sebuah siklus yang memiliki tahapan 4R (Soroto et al., 2018), yaitu: 
1) Retrieve

Tahap untuk mengambil kembali dengan kasus yang paling mirip dengan kasus terbaru. Dimulai dari penelusuran kasus sampai ditemukan kecocokan yang nilai nya paling tinggi dengan kasus sebelumnya. Pada proses ini dilakukan identifikasi masalah, pencocokan dan seleksi.

2) Reuse

Proses menggunakan kembali informasi dan pengetahuan kedalam kasus yang baru berdasarkan tingkat kemiripan yang paling relevan dengan kasus lama. Pada tahap ini dimungkinkan adanya keperluan adaptasi atas solusi yang akan diberikan atas masalah tersebut.

3) Revise

Pada tahap revise ini dilakukan proses meninjau kembali solusi yang didapat, kemudian mengevaluasi kembali dan memperbaiki solusi tersebut agar cocok dengan masalah yang ada.

4) Retain

Didalam proses terakhir ini sistem akan menyimpan kasus baru yang telah berhasil mendapatkan solusi agar pengetahuannya dapat digunakan oleh kasus-kasus selanjutnya yang mirip dengan kasus tersebut. Jika solusi tidak berhasil, maka perlu diadakan pengujian kembali.

b Similarity

Kemiripan (similarity) adalah langkah yang digunakan untuk mengenali kesamaan atau kemiripan antara kasus-kasus yang tersimpan dengan kasus yang baru. Kasus dengan nilai similarity paling besar dianggap sebagai kasus yang paling mirip. Nilai similarity berkisar antara 0 sampai 1 (Syaputra, 2019). Berikut adalah rumus perhitungan similarity:

Similarity $(p c)=\frac{S 1 * W 1+S 2 * W 2+S 3 * W 3 \ldots \ldots+S n * W n}{W 1+W 2+W 3 \ldots+W n} \ldots$

Keterangan:

S : Similarity (Nilai kemiripan dimana $0=$ Mirip \& 1 = Tidak mirip)

$\mathrm{W}$ : Weight (bobot yang diberi)

$\mathrm{n}$ : Jumlah atribut dalam setiap kasus

Perhitungan metode Case-Based Reasoning pada penelitian ini menggunakan similarity atau kemiripan. Diberikan beberapa kondisi kejiwaan sesuai dengan ciri-ciri dari setiap kepribadian, pengguna akan memilih kecocokan dengan data yang diberikan. Pembobotan dilakukan untuk mengetahui seberapa tinggi kemiripan kondisi kejiwaan dari pengguna dengan kondisi kejiwaan yang diberikan sistem. Tingkat dan nilai bobot ditentukan dari hasil pembelajaran pada kasus oleh pihak terkait. Parameter dari pembobotan terdapat pada Tabel 1.

Tabel 1. Parameter Bobot

\begin{tabular}{cc}
\hline Parameter & Bobot \\
\hline Rendah & 1 \\
\hline Sedang & 2 \\
\hline Tinggi & 3 \\
\hline
\end{tabular}

Dari hasil kecocokan yang sudah ditentukan oleh pengguna, maka langkah selanjutnya adalah melakukan perhitungan dengan rumus similarity, untuk menemukan tipe kepribadian yang cocok dengan data yang di input oleh pengguna.

\section{Teknik Pengumpulan Data}

Pada pembuatan suatu sistem pakar diperlukan teknik pengumpulan data. Aktivitas pengumpulan data bertujuan untuk mengumpulkan data yang valid dengan cara ilmiah untuk menunjang pelaksanaan dan pencapaian tujuan dari penelitian . Beberapa teknik yang digunakan peneliti dalam melakukan pengumpulan data meliputi:

a) Observasi, pada penelitian ini dilakukan pengamatan secara langsung ke tempat riset yaitu SMP IT Daarul Hikmah. Observasi dilakukan agar dapat mengamati kasus atau permasalahan yang ada di SMP IT Daarul Hikmah seperti kegiatan pembelajarannya.

b) Wawancara, dilakukan agar mendapatkan keterangan yang diperlukan dalam penelitian. Dalam hal ini data didapatkan hasil dari wawancara dengan Kepala Sekolah SMP IT Daarul Hikmah, guru bimbingan konseling, dan pamong atau pendidik.

c) Kuesioner, dilakukan dengan cara menyebarkan angket kepada responden dengan beberapa pertanyaan yang perlu dijawab.

d) Studi Pustaka, dilakukan agar mendapatkan pemahaman mengenai penelitian dengan cara mengkaji jurnal penelitian yang relevan dan sumber lain seperti buku dan internet.

3. Pengembangan Sistem

Metode pengembangan sistem yang dipakai pada penelitian identitifikasi kepribadian siswa adalah model Expert System Development Life Cycle (ESDLC). Penggunaan model ESDLC tersebut hanya akan meliputi tahapan penilaian, akuisisi pengetahuan, desain, serta pengujian terhadap sistem pakar berbasis website (Nurdiawan \& Fatimah, 2016).

a. Penilaian (Assessment), dilakukan proses penentuan kelayakan dari permasalahan, tujuan, serta ruang lingkup dari permasalahan maupun sistem pakar yang akan dikembangkan.

b. Akuisisi Pengetahuan (Knowledge Acquisition), dilakukan pengumpulan data berupa tipe kepribadian seseorang, ciri-ciri dari setiap kepribadian, serta komunikasi yang perlu dilakukan sesuai dengan kepribadiannya. Pengetahuan didapatkan dari beberapa buku serta wawancara dengan pihak sekolah.

c. Desain (Design), pada tahap ini dilakukan perancangan sistem pakar menggunakan diagram UML dan perancangan basis data dengan ERD. Kemudian melakukan implementasi dengan membangun sebuah website sesuai dengan rancangan sistem pakar yang telah dibuat. 
d. Pengujian (Testing), tahap ini dilakukan agar diketahui bahwa sistem pakar berbasis website sudah sesuai dengan kebutuhan dan tujuannya, serta menghindari bugs pada sistem. Metode pengujian yang akan dilakukan pada sistem pakar menggunakan Black-Box testing.

\section{HASIL DAN PEMBAHASAN}

Pada bagian ini dijelaskan hasil penelitian sistem pakar identifikasi kepribadian siswa berbasis website di di SMP IT Daarul Hikmah serta diberikan pembahasan studi kasus yang komprehensif menggunakan metode Case-Based Reasoning (CBR).

1. Assesment

Pada penilaian (assessment) ditentukan kelayakan perangkat keras serta perangkat lunak yang compatible dalam mengembangkan website dari sistem pakar identifikasi kepribadian siswa.

a. Kebutuhan Hardware

Perangkat keras atau hardware merupakan komponen dari personal computer (PC) yang bersifat fisik. Berikut merupakan perangkat keras yang digunakan di dalam penelitian ini yang tercantum pada Tabel 2.

Tabel 2. Spesifikasi Perangkat Keras

\begin{tabular}{cll}
\hline No. & \multicolumn{1}{c}{ Komponen } & \multicolumn{1}{c}{ Spesifikasi } \\
\hline 1. & Processor & $\begin{array}{l}\text { Intel Celeron N4000 } \\
\text { dual-core 1,1Ghz }\end{array}$ \\
\hline 2. & RAM & 4GB DDR4 2133Mhz \\
\hline 3. & GPU (Graphic & Intel UHD Graphic \\
& Processing Unit) & 600 \\
\hline 4. & Harddisk & 1TB 5400 rpm \\
\hline 5. & Display & 14'’ (1366x768) \\
& & Glare 60Hz Panel \\
\hline
\end{tabular}

\section{b. Kebutuhan Software}

Perangkat lunak atau software merupakan piranti di dalam komputer yang berisi kumpulan instruksi atau program untuk melakukan sesuatu. Berikut merupakan perangkat lunak yang digunakan dalam membangun website sistem pakar pada penelitian ini yang tercantum di dalam Tabel 3 .

Tabel 3. Spesifikasi Perangkat Lunak

\begin{tabular}{cll}
\hline No. & \multicolumn{1}{c}{ Komponen } & \multicolumn{1}{c}{ Spesifikasi } \\
\hline 1. & OS & Windows 10 64-bit \\
\hline 2. & Code Editor & Visual Studio Code \\
\hline 3. & UML Case Tool & Visual Paradigm 16.3 \\
\hline 4. & Browser & Google Chrome \\
\hline 5. & Web Server & XAMPP 3.2.3 \\
\hline
\end{tabular}

\section{Knowledge Acquisition}

Akuisisi pengetahuan (knowledge acquisition) dilakukan pengumpulan pengetahuan yang berkaitan dengan kepribadian seseorang serta aturan dan metode dalam pembuatan sistem pakar menggunakan metode CBR. a. Basis Pengetahuan

Basis pengetahuan berisi data beberapa tipe kepribadian beserta ciri-ciri dan bobotnya sesuai dengan kondisi mentalnya, kemudian diberikan solusi komunikasi yang disarankan.

Tabel 4. Tipe Kepribadian

\begin{tabular}{clc}
\hline No. & Tipe Kepribadian & Kode \\
\hline 1. & Koleris & T1 \\
\hline 2 & Sanguinis & T2 \\
\hline 3. & Melankolis & T3 \\
\hline 4. & Plegmatis & T4 \\
\hline
\end{tabular}

Pada Tabel 4 terdapat empat tipe kepribadian dengan memiliki ciri-ciri khusus yang menggambarkan tipe kepribadian seseorang. Setiap ciri-ciri memiliki bobot yang menjadi parameter dan membedakan tingkatan nilainya.

Ciri-ciri dan bobot tipe kepribadian koleris ditunjukkan pada Tabel 5.

Tabel 5. Tipe Kepribadian Koleris

\begin{tabular}{clcc}
\hline No. & \multicolumn{1}{c}{ Koleris } & Kode & Bobot \\
\hline 1. & $\begin{array}{l}\text { Keras kepala dan } \\
\text { berkemauan tinggi }\end{array}$ & K01 & 3 \\
\hline 2. & $\begin{array}{l}\text { Mandiri dan cepat } \\
\text { mengambil } \\
\text { keputusan }\end{array}$ & K02 & 3 \\
\hline 3. & $\begin{array}{l}\text { Kurang simpati dan } \\
\text { cuek }\end{array}$ & K03 & 3 \\
\hline 4. & $\begin{array}{l}\text { Aktif dan suka } \\
\text { berpetualang }\end{array}$ & K04 & 2 \\
\hline 5. & Suka tantangan & K05 & 2 \\
\hline 6. & $\begin{array}{l}\text { Independen dan suka } \\
\text { mengatur }\end{array}$ & K06 & 2 \\
\hline 7. & $\begin{array}{l}\text { Mudah marah dan } \\
\text { memaksa }\end{array}$ & K07 & 1 \\
\hline 8. & Kompetitif & K08 & 1 \\
\hline 9. & $\begin{array}{l}\text { Suka berpendapat } \\
\text { dan tegas }\end{array}$ & K09 & 1 \\
\hline
\end{tabular}

Ciri-ciri dan bobot tipe kepribadian sanguitis ditunjukkan pada Tabel 6.

Tabel 6. Tipe Kepribadian Sanguinis

\begin{tabular}{clcc}
\hline No. & \multicolumn{1}{c}{ Sanguinis } & Kode & Bobot \\
\hline 1. & Kekanakan & S01 & 3 \\
\hline 2. & Emosi labil & S02 & 3 \\
\hline 3. & Ekspresif & S03 & 3 \\
\hline 4. & Lincah & S04 & 2 \\
\hline 5. & Mudah bergaul & S05 & 2 \\
\hline 6. & Tidak konsisten & S06 & 2 \\
\hline 7. & Berantakan dan & S07 & 1 \\
& pelupa & & \\
\hline 8. & Berjiwa sosial tinggi & S08 & 1 \\
\hline 9. & Banyak bicara & S09 & 1 \\
\hline
\end{tabular}

Ciri-ciri dan bobot tipe kepribadian melankolis ditunjukkan pada Tabel 7. 
Tabel 7. Tipe Kepribadian Melankolis

\begin{tabular}{clcc}
\hline No. & \multicolumn{1}{c}{ Melankolis } & Kode & Bobot \\
\hline 1. & Penakut & M01 & 3 \\
\hline 2. & Perfeksionis & M02 & 3 \\
\hline 3. & Menyendiri & M03 & 3 \\
\hline 4. & Kritis & M04 & 2 \\
\hline 5. & Sangat fokus & M05 & 2 \\
\hline 6. & $\begin{array}{l}\text { Lamban dalam hal } \\
\text { baru }\end{array}$ & M06 & 2 \\
\hline 7. & Menarik diri & M07 & 1 \\
\hline 8. & Pendiam & M08 & 1 \\
\hline 9. & $\begin{array}{l}\text { Serius dan mudah } \\
\text { tersinggung }\end{array}$ & M09 & 1 \\
\hline
\end{tabular}

Tabel 8. Tipe Kepribadian Plegmatis

\begin{tabular}{clcc}
\hline No. & \multicolumn{1}{c}{ Plegmatis } & Kode & Bobot \\
\hline 1. & Ceria & $\mathrm{P} 01$ & 3 \\
\hline 2. & Ramah dan tenang & $\mathrm{P} 02$ & 3 \\
\hline 3. & Monoton & $\mathrm{P} 03$ & 3 \\
\hline 4. & Mudah beradaptasi & $\mathrm{P} 04$ & 2 \\
\hline 5. & Mudah menyerah & $\mathrm{P} 05$ & 2 \\
\hline 6. & $\begin{array}{l}\text { Tidak suka menonjolkan } \\
\text { diri sendiri }\end{array}$ & $\mathrm{P} 06$ & 2 \\
\hline 7. & Tidak suka kejutan & $\mathrm{P} 07$ & 1 \\
\hline 8. & Menghindari konflik & $\mathrm{P} 08$ & 1 \\
\hline 9. & Pendengar yang baik & $\mathrm{P} 09$ & 1 \\
\hline
\end{tabular}

\section{b. Aturan (Rule)}

Aturan atau rule diperoleh dari basis pengetahuan yang kemudian disusun sehingga dapat dijadikan aturan dalam perhitungan pada Tabel 9.

Tabel 9. Basis Pengetahuan Aturan Kepribadian

\begin{tabular}{|c|c|}
\hline No. & Aturan \\
\hline 1 & $\begin{array}{l}\text { IF nilai similarity koleris > nilai } \\
\text { similarity sanguinis } \\
\text { AND nilai similarity koleris > nilai } \\
\text { similarity melankolis } \\
\text { AND nilai similarity koleris > nilai } \\
\text { similarity Plegmatis } \\
\text { THEN "Koleris" }\end{array}$ \\
\hline 2 & $\begin{array}{l}\text { IF nilai similarity sanguinis > nilai } \\
\text { similarity koleris } \\
\text { AND nilai similarity sanguinis > nilai } \\
\text { similarity melankolis } \\
\text { AND nilai similarity sanguinis > nilai } \\
\text { similarity Plegmatis } \\
\text { THEN "Sanguinis" }\end{array}$ \\
\hline 3 & $\begin{array}{l}\text { IF nilai similarity melankolis > nilai } \\
\text { similarity koleris } \\
\text { AND nilai similarity melankolis > } \\
\text { nilai similarity Sanguinis } \\
\text { AND nilai similarity melankolis > } \\
\text { nilai similarity Plegmatis } \\
\text { THEN "melankolis" }\end{array}$ \\
\hline 4 & $\begin{array}{l}\text { IF nilai similarity plegmatis > nilai } \\
\text { similarity koleris } \\
\text { AND nilai similarity plegmatis > nilai } \\
\text { similarity Sanguinis } \\
\text { AND nilai similarity plegmatis > nilai } \\
\text { similarity melankolis } \\
\text { THEN "plegmatis" }\end{array}$ \\
\hline
\end{tabular}

\section{c. Metode Case-Based Reasoning (CBR)}

Pada metode CBR dilakukan beberapa tahapan untuk memproses kasus baru mulai dari pencocokan, perhitungan, dan solusinya.

1) Retrive

Proses retrive yaitu pencarian kecocokan ciri-ciri kepribadian antara kasus baru dengan basis pengetahuan. Contoh studi kasus baru dengan ciri-ciri yang dipilih untuk dicari kemiripannya pada Tabel 10.

Tabel 10. Studi Kasus Identifikasi Kepribadian

\begin{tabular}{cl}
\hline No. & \multicolumn{1}{c}{ Studi Kasus } \\
\hline 1 & Keras kepala \& kemauan tinggi \\
\hline 2 & Aktif dan suka berpetualang \\
\hline 3 & Mudah marah \& memaksa \\
\hline 4 & Kompetitif \\
\hline 5 & Suka berpendapat \& tegas \\
\hline 6 & Emosi labil \\
\hline 7 & Mudah bergaul \\
\hline 8 & Tidak konsisten \\
\hline 9 & Berantakan \& pelupa \\
\hline 10 & Banyak bicara \\
\hline 11 & Kritis \\
\hline 12 & Lamban dalam hal baru \\
\hline 13 & Ceria \\
\hline 14 & Mudah menyerah \\
\hline
\end{tabular}

Pada Tabel 10 dari ke empat belas ciri-ciri kepribadian yang dipilih, maka dapat dikelompokan berdasarkan tipe kepribadian dengan dilengkapi kode serta bobot dari ciri-ciri kepribadian. Pencocokan tipe kepribadian dapat dilihat pada Tabel 11 untuk tipe kepribadian koleris, Tabel 12 untuk kepribadian sanguinis, Tabel 13 untuk kepribadian melankolis, dan Tabel 14 untuk kepribadian plegmatis.

Tabel 11. Kecocokan Tipe Kepribadian Koleris

\begin{tabular}{clcc}
\hline No. & Ciri-ciri Terpilih & Kode & Bobot \\
\hline 1. & $\begin{array}{l}\text { Keras kepala dan } \\
\text { berkemauan tinggi }\end{array}$ & K01 & 3 \\
\hline 2. & $\begin{array}{l}\text { Aktif dan suka } \\
\text { berpetualang }\end{array}$ & K04 & 2 \\
\hline 3. & $\begin{array}{l}\text { Mudah marah dan } \\
\text { memaksa }\end{array}$ & K07 & 1 \\
\hline 4. & Kompetitif & K08 & 1 \\
\hline 5. & $\begin{array}{l}\text { Suka berpendapat } \\
\text { dan tegas }\end{array}$ & K09 & 1 \\
\hline
\end{tabular}

Tabel 12. Kecocokan Tipe Kepribadian Sanguinis

\begin{tabular}{clcc}
\hline No. & Ciri-ciri Terpilih & Kode & Bobot \\
\hline 1. & Emosi labil & S02 & 3 \\
\hline 2. & Mudah bergaul & S05 & 2 \\
\hline 3. & Tidak konsisten & S06 & 2 \\
\hline 4. & $\begin{array}{l}\text { Berantakan dan } \\
\text { pelupa }\end{array}$ & S07 & 1 \\
\hline 5. & Banyak bicara & S09 & 1 \\
\hline
\end{tabular}


Tabel 13. Kecocokan Tipe Kepribadian Melankolis

\begin{tabular}{clcc}
\hline No. & Ciri-ciri Terpilih & Kode & Bobot \\
\hline 1. & Kritis & M04 & 2 \\
\hline 2. & $\begin{array}{l}\text { Lamban dalam hal } \\
\text { baru }\end{array}$ & M06 & 2 \\
\hline
\end{tabular}

Tabel 14. Kecocokan Tipe Kepribadian Plegmatis

\begin{tabular}{clcc}
\hline No. & Ciri-ciri Terpilih & Kode & Bobot \\
\hline 1. & Ceria & P01 & 3 \\
\hline 2. & Mudah menyerah & P05 & 2 \\
\hline
\end{tabular}

\section{2) Reuse}

Pada proses reuse atau penggunaan kembali data yang sudah didapatkan kemudian dilakukan perhitungan kemiripan antara kasus yang baru dengan kasus yang sudah ada sebelumnya menggunakan rumus perhitungan similarity, sehingga didapatkan nilai kemiripan yang paling tinggi sesuai dengan tipe kepribadiannya sebagai berikut:

a) Kemiripan dengan Koleris:

$$
\begin{aligned}
\text { Similarity } & =\frac{1 * 3+0 * 3+0 * 3+1 * 2+0 * 2+0 * 2+1 * 1+1 * 1+1 * 1}{3+3+3+2+2+2+1+1+1} \\
& =\frac{8}{18}=0,444 * 100=44,4 \%
\end{aligned}
$$

b) Kemiripan dengan Sanguinis

$$
\begin{aligned}
\text { Similarity } & =\frac{0 * 3+1 * 3+0 * 3+0 * 2+1 * 2+1 * 2+1 * 1+0 * 1+1 * 1}{3+3+3+2+2+2+1+1+1} \\
& =\frac{9}{18}=0,5 * 100=50 \%
\end{aligned}
$$

c) Kemiripan dengan Melankolis

$$
\begin{aligned}
\text { Similarity } & =\frac{0 * 3+0 * 3+0 * 3+1 * 2+0 * 2+1 * 2+0 * 1+0 * 1+0 * 1}{3+3+3+2+2+2+1+1+1} \\
& =\frac{4}{18}=0,222 * 100=22,2 \%
\end{aligned}
$$

d) Kemiripan dengan Plegmatis

$$
\begin{aligned}
\text { Similarity } & =\frac{1 * 3+0 * 3+0 * 3+0 * 2+1 * 2+0 * 2+0 * 1+0 * 1+0 * 1}{3+3+3+2+2+2+1+1+1} \\
& =\frac{5}{18}=0,278 * 100=27,8 \%
\end{aligned}
$$

Dari perhitungan tersebut menunjukkan bahwa nilai kemiripan kasus baru dengan tipe kepribadian koleris sebanyak 44,4\%, kemiripan dengan tipe kepribadian sanguinis sebanyak $50 \%$, kemiripan dengan tipe kepribadian melankolis $22,2 \%$ dan kemiripan dengan tipe kepribadian plegmatis sebanyak 27,8\%. Maka dapat disimpulkan bahwa kasus baru memiliki nilai kemiripan paling tinggi dengan kepribadian sanguinis dengan nilai $50 \%$.

3). Revise

Pada proses ini solusi akan ditinjau oleh pakar apakah perlu dievaluasi dan diperbaiki kembali solusi yang didapat agar cocok dengan kasus yang ada. Solusi perlu direvisi ulang oleh pakar jika kasus memiliki nilai yang sangat rendah.

4) Retain

Pada tahap ini, kasus baru yang telah menemukan solusi yang tepat akan disimpan ke dalam basis pengetahuan oleh pakar dan digunakan kembali jika terjadi kasus yang mirip. Jika solusi tidak berhasil, maka perlu diadakan pengujian kembali agar mendapatkan solusi yang tepat.

\section{Design}

Pada tahap desain berisi perancangan sistem pakar menggunakan model UML dan perancangan database dengan ERD.

a. Perancangan UML

Desain sistem pakar identifikasi kepribadian siswa berbasis website dengan UML berikut ini:

1) Use Case Diagram

Digambarkan use case diagram dari setiap actor yang berinteraksi dengan sistem pakar dengan memiliki dua actor yaitu sebagai user dan admin.

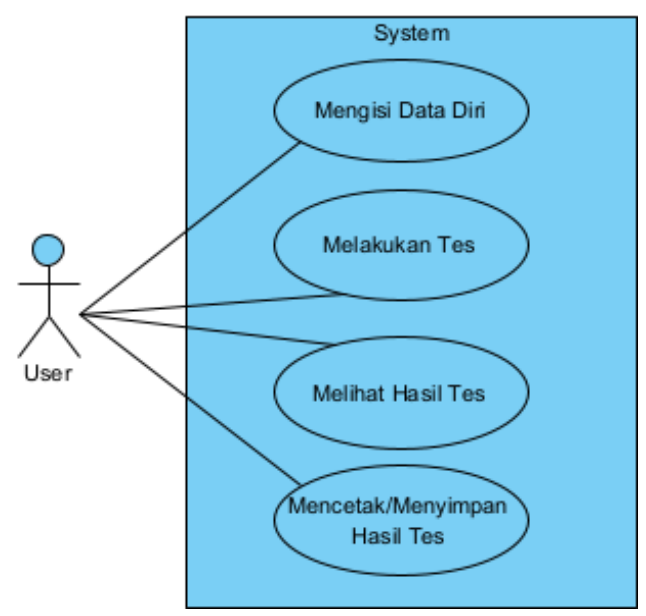

Gambar 1. Use Case Diagram User

Pada Gambar 1 menunjukkan pemodelan use case diagram user terdapat actor siswa, guru, atau orang tua dapat mengisi data diri, melakukan tes, melihat hasil tes, dan menyimpan hasil tes.

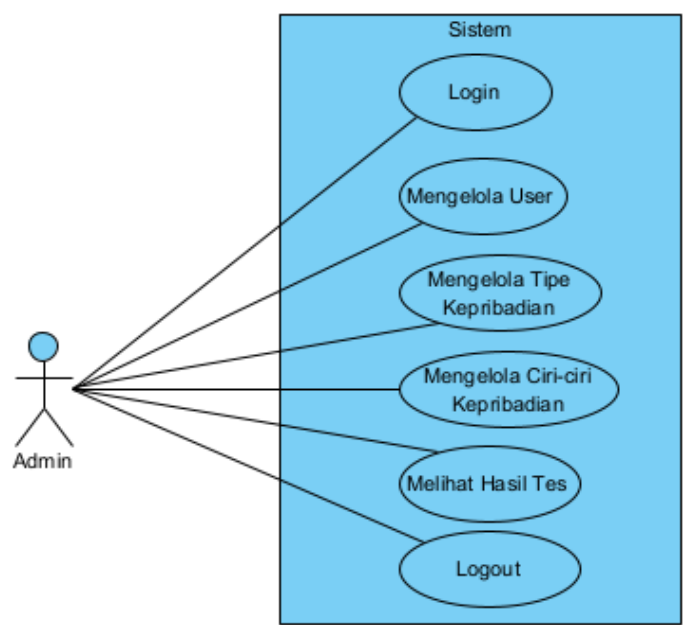

Gambar 2. Use Case Diagram Admin

Pada Gambar 2 menggambarkan use case diagram admin yang dapat melakukan login, mengelola user, tipe kepribadian, ciri-ciri kepribadian, melihat hasil tes, serta logout.

2) Class Diagram

Penggambaran sistem pakar penentuan kepribadian siswa berbasis website dengan class diagram ditunjukkan pada Gambar 3. 


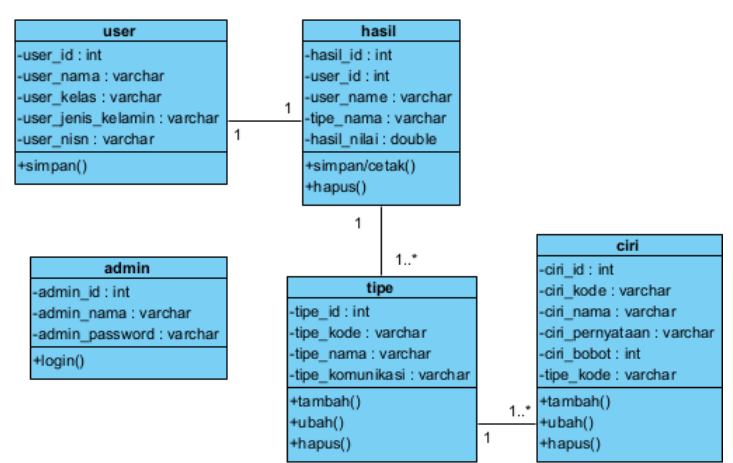

Gambar 3. Class Diagram Sistem Pakar

Pada Gambar 3 menunjukkan bahwa class dari sistem pakar penentuan kepribadian siswa terdiri dari lima kelas. Kelas user berasosiasi dengan kelas hasil, dimana satu user dapat memiliki satu hasil tes. Kelas hasil berasosiasi dengan kelas tipe, satu hasil tes terdapat beberapa tipe dengan nilai yang berbeda. Kelas tipe berasosiasi dengan kelas ciri, dimana satu tipe memiliki beberapa ciri.

b. Perancangan Basis Data

Database atau basis data dari sistem pakar identifikasi kepribadian siswa digambarkan dengan membuat rancangan ERD yang memodelkan tabeltabel serta relasinya pada Gambar 4.

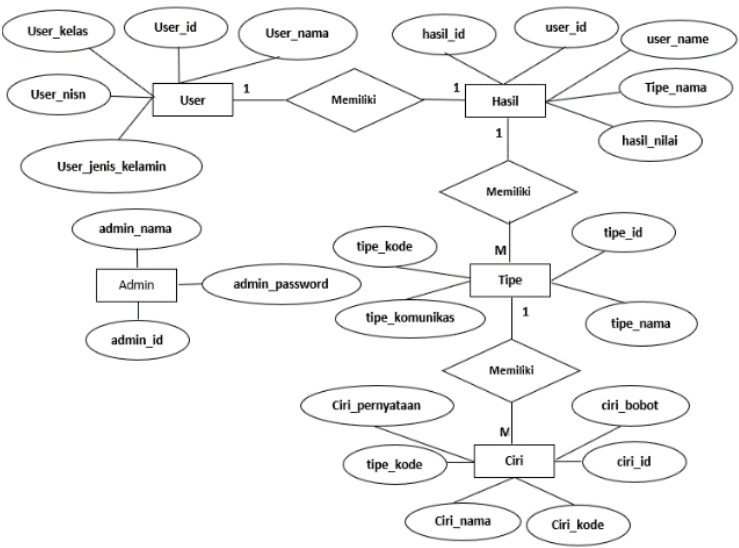

Gambar 4. Perancangan ERD

Pada Gambar 4 menunjukkan entitas dan relasi didalam database yang terdiri dari user, hasil, tipe, ciri dan admin. Tabel user memiliki relasi dengan tabel hasil (kardinalitas one to one). Tabel hasil juga memiliki relasi dengan tabel tipe, dan tabel tipe memiliki relasi dengan tabel ciri. Namun tabel admin tidak memiliki relasi dengan tabel lainnya.

c. Antarmuka Pengguna

Tampilam user interface atau antarmuka pengguna dari sistem pakar identifikasi kepribadian siswa bagi user dan admin dalam melakukan interaksi dengan website sebagai berikut:

a. Antarmuka User

Pada antarmuka user yang digunakan oleh siswa, guru, ataupun orang tua pada Gambar 5.

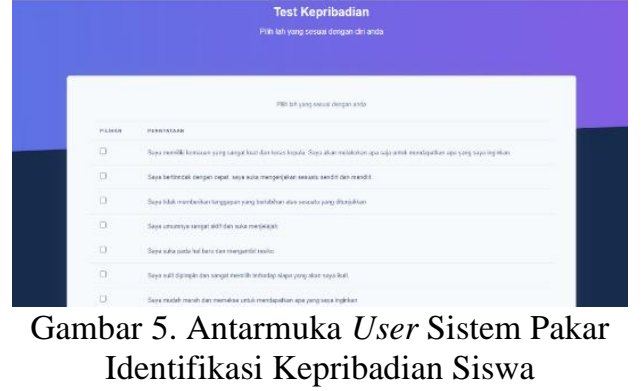

Pada Gambar 5 menampilkan halaman sistem pakar yang digunakan oleh user meliputi mengisi data pribadi, melakukan tes, melihat hasil tes, dan mencetak atau menyimpan hasil tes.

b. Antarmuka Admin

Pada antarmuka admin yang digunakan oleh pakar ditampilkan pada Gambar 6.

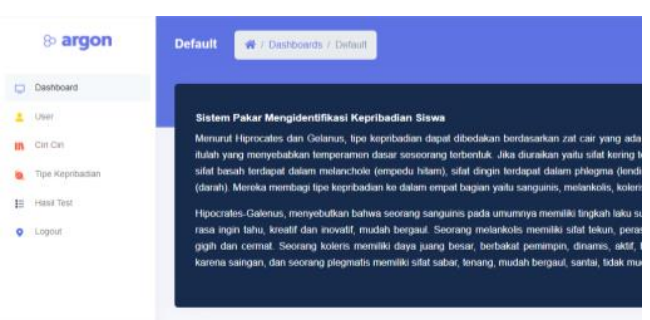

Gambar 6. Antarmuka Admin Sistem Pakar Identifikasi Kepribadian Siswa

Pada Gambar 6 menampilkan halaman sistem pakar oleh admin meliputi login, mengelola user, mengelola tipe kepribadian, mengelola ciri-ciri kepribadian, melihat hasil test, dan logout.

4. Testing

Pada bagian ini pengujian dilakukan terhadap sistem pakar dengan black-box testing dan penerimaan pengguna menggunakan metode Technology Acceptance Model (TAM).

a. Pengujian Sistem Pakar

Pengujian terhadap sistem dilakukan dengan menggunakan Black-box testing atau pengujian Black-Box. Pengujian dapat dilihat pada Tabel 15.

Tabel 15. Hasil Pengujian Black-Box

\begin{tabular}{|c|c|c|c|}
\hline No. & Actor & Skenario & Kesimpulan \\
\hline 1. & \multirow{4}{*}{ User } & Mengisi data diri & Sukses \\
\hline 2. & & Melakukan tes & Sukses \\
\hline 3. & & Melihat hasil tes & Sukses \\
\hline 4. & & Mencetak hasil tes & Sukses \\
\hline 5. & \multirow{6}{*}{ Admin } & Melakukan login & Sukses \\
\hline 6. & & $\begin{array}{l}\text { Mengelola data } \\
\text { users }\end{array}$ & Sukses \\
\hline 7. & & $\begin{array}{l}\text { Mengelola tipe } \\
\text { kepribadian }\end{array}$ & Sukses \\
\hline 8. & & $\begin{array}{l}\text { Mengelola ciri- } \\
\text { ciri kepribadian }\end{array}$ & Sukses \\
\hline 9. & & Melihat hasil tes & Sukses \\
\hline 10. & & Melakukan logout & Sukses \\
\hline
\end{tabular}


b. Pengujian Penerimaan Pengguna

Disebarkan kuesioner untuk mengetahui kondisi sistem pakar sesuai dengan harapan pengguna menggunakan TAM. Nilai skala likert yang dipakai 1-5 dengan keterangan berikut ini:

1) Sangat tidak setuju dengan nilai 1

2) Tidak setuju dengan nilai 2

3) Netral dengan nilai 3

4) Setuju dengan nilai 4

5) Sangat setuju dengan nilai 5

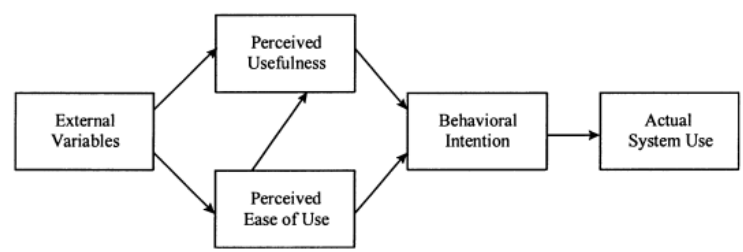

Sumber: (Yakubu \& Kah, 2020)

Gambar 7. Technology Acceptance Model

Pada Gambar 7 penerimaan pengguna terhadap suatu sistem ditentukan oleh beberapa variabel serta indikatornya masing-masing yaitu:

1. Perceived Usefulnes:

P1: Menggunakan website tes kepribadian dapat meningkatkan kinerja saya $=4,25$

P2: Menggunakan website tes kepribadian dapat meningkatkan produktivitas saya $=4,125$

P3: Menggunakan website tes kepribadian dapat meningkatkan efektifitas saya $=4,25$

P4: Website tes kepribadian berguna bagi saya $=$ 4,375

2. Perceived Easy to Use:

P5: Website tes kepribadian mudah dipahami $=$ 4,125

P6: Website tes kepribadian mudah tidak memerlukan banyak upaya $=4,375$

P7: Website tes kepribadian mudah digunakan $=$ 4,25

P8: Saya mudah untuk terampil dalam menggunakan website tes kepribadian = 4,375

3. Bahavioral Intention:

P9: Saya berniat untuk terus menggunakan website tes kepribadian $=3,75$

P10: Saya memprediksi akan memakai website tes kepribadian di waktu mendatang $=4,375$

4. Actual System Use:

P11: Saya akan sering menggunakan website tes kepribadian $=3,625$

P12: Menjalankan website tes kepribadian dilakukan dengan waktu yang cepat $=4,375$

P13: Secara keseluruhan saya puas dengan kinerja website tes kepribadian $=4,375$

\section{KESIMPULAN}

Hasil pembahasan model ESDLC yang telah dilakukan pada penelitian sistem pakar identifikasi kepribadian siswa menggunakan metode CBR dapat diambil kesimpulan berikut ini:

1. Sistem pakar yang dikembangkan pada penelitian ini mampu memudahkan orang tua dalam melakukan konsultasi awal kepribadian anaknya. Pada sistem ini disedikan beberapa pilihan kondisi mental yang sesuai dengan kajian dari pakar atau psikiater.

2. Metode Case-Based Reasoning (CBR) yang telah diterapkan pada sistem pakar sangat tepat dalam mengidentifikasi kepribadian siswa. Pada metode CBR dilakukan perhitungan berdasarkan nilai kemiripan dari kasus baru dengan data yang sudah disediakan oleh pakar.

3. Sistem pakar menggunakan metode CBR berbasis website menyediakan dukungan yang bermanfaat bagi pihak SMP IT Daarul Hikmah. Pengujian pengguna dengan acceptance testing menunjukkan bukti bahwa responden memberikan umpan balik dengan rata-rata tingkat kepuasan pada kategori baik.

\section{REFERENSI}

Ajhuri, F. K. (2019). Psikologi Perkembangan: Pendekatan Sepanjang Rentang Kehidupan. Jogjakarta: Penebar Media Pustaka.

Ernawati, D., Yusda, R. A., \& Putra, G. M. (2021). Analisis Penyakit Pada Tanaman Cabai dengan Metode Case Based Reasoning Berbasis Web. J-Com, 1(1), 43-48.

Gulo, A. A. H. S., \& Syahrizal, M. (2018). PERANCANGAN APLIKASI SISTEM PAKAR MENDIAGNOSA PENYAKIT HEMOFILIA PADA MANUSIA MENERAPKAN METODE CASE BASED REASONING. Jurnal Pelita Informatika, 6(3), 278-283.

Hardianto, R. (2018). Sistem Pakar Penentuan Tipe Kepribadian Siswa Sekolah Dasar Menggunakan Metode Case Based Reasoning. INTECOMS: Journal of Information Technology and Computer Science, 1(2), 240250. https://doi.org/10.31539/intecoms.v1i2.298

Hardianto, R., \& Kusuma, C. (2019). Rancang Bangun Sistem Pakar Penentuan Kepribadian. Jurnal Sistem Komputer Dan Informatika (JSON), 1(1), 45. https://doi.org/10.30865/json.v1i1.1385

Malana, E., \& Hasibuan, M. S. (2020). Expert System for Identifying Students'Behavior and Personality Through Cased-Based Reasoning at The State Junior High School 5 Bandar Lampung. International Conference on Information Technology and Business (ICITB), 202-207. 
Nurdiawan, H., \& Fatimah, D. D. S. (2016). Pengembangan Sistem Pakar Diagnosis Penyakit Tanaman Tomat Berbasis Visual Prolog. Jurnal Algoritma, 13(1), 114-121.

Rahim, R., Purba, W., Khairani, M., \& Rosmawati, R. (2019). Online Expert System for Diagnosis Psychological Disorders Using Case-Based Reasoning Method. Journal of Physics: Conference Series, 1381(1), 12044.

Sahlan, A. K. (2018). Mendidik Perspekif Psikologi (1st ed.). Deepublish.

Soroto, A. S., Fuad, A., \& Lutfi, S. (2018). Penerapan Metode Case Based Reasoning (Cbr) Untuk Sistem Penentuan Status Gunung Gamalama. JIKO (Jurnal Informatika Dan Komputer), $1(2)$, $70-75$. https://doi.org/10.33387/jiko.v1i2.771

Syaputra, N. H. (2019). Perancangan Aplikasi Sistem Pakar Diagnosa Kerusakan Lift Dengan Menggunakan Metode Case Based Reasoning ( CBR ). Jurinal Riset Komputer (JURIKOM), 6(4), 421-428.

Yakubu, M. N., \& Kah, M. (2020). Nigerian Instructors' Acceptance of Learning Management Systems: A Structural Modeling Approach. 2020 IST-Africa Conference, ISTAfrica 2020, 1-10. 